Rapid Reviews COVID-19

\title{
Reviews of "Deaths of Despair and the Incidence of Excess Mortality in 2020"
}

Rudi Rocha ${ }^{1}$, Tom Vogl ${ }^{2}$, Nicholas Reynolds ${ }^{3}$

${ }^{1}$ FGV-EAESP: Fundacao Getulio Vargas Escola de Administracao de Empresas de Sao Paulo, Economics, Brazil,

${ }^{2}$ UCSD, Economics, ${ }^{3}$ Assistant Professor in Economics, University of Essex

Published on: Apr 13, 2021

DOI: $10.1162 / 2 \mathrm{e} 3983 f 5.7 \mathrm{dd} 4 \mathrm{db} 01$

License: Creative Commons Attribution 4.0 International License (CC-BY 4.0). 
To read the original manuscript, click the link above.

Summary of Reviews: Reviewers disagree on this preprint. One finds a major methodological flaw that makes the conclusions unreliable; the other finds the analysis general but reliable, and suggests that the findings should engage other work on the mental health consequences of the pandemic.

\section{Reviewer 1}

Reviewer 2 (Rudi Rocha)

Reviewer 3 (Tom Vogl)

\section{Reviewer 4 (Nicholas Reynolds)}

RR:C19 Strength of Evidence Scale Key.

प्रमप्र = Misleading

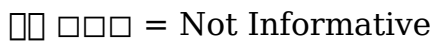

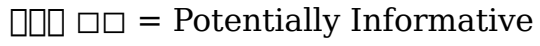

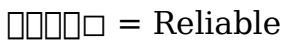

प्राप्र = Strong

To read the reviews, click the links below. 